\title{
Questions about COVID-19 associated coagulopathy: possible answers from the viscoelastic tests
}

\author{
Vittorio Pavoni ${ }^{1} \cdot$ Lara Gianesello ${ }^{2}$ (D) Maddalena Pazzi ${ }^{1} \cdot$ Pietro Dattolo $^{3} \cdot$ Domenico Prisco $^{4}$
}

Received: 20 May 2021 / Accepted: 9 July 2021 / Published online: 15 July 2021

(c) The Author(s), under exclusive licence to Springer Nature B.V. 2021

\begin{abstract}
Abnormal coagulation parameters are often observed in patients with coronavirus disease 2019 (COVID-19) and the severity of derangement has been associated with a poor prognosis. The COVID-19 associated coagulopathy (CAC) displays unique features that include a high risk of developing thromboembolic complications. Viscoelastic tests (VETs), such as thromboelastometry (ROTEM), thromboelastography (TEG) and Quantra Hemostasis Analyzer (Quantra), provide "dynamic" data on clot formation and dissolution; they are used in different critical care settings, both in hemorrhagic and in thrombotic conditions. In patients with severe COVID-19 infection VETs can supply to clinicians more information about the CAC, identifying the presence of hypercoagulable and hypofibrinolysis states. In the last year, many studies have proposed to explain the underlying characteristics of CAC; however, there remain many unanswered questions. We tried to address some of the important queries about CAC through VETs analysis.
\end{abstract}

Keywords COVID-19 · Coagulopathy $\cdot$ Viscoelastic tests $\cdot$ Thromboembolic events

\section{Introduction}

Severe acute respiratory syndrome coronavirus 2 (SARS$\mathrm{CoV}-2$ ) infection is characterized by a diffuse endothelial dysfunction and a hyperinflammation state that leads to a cytokine storm which enhances the risk of thrombotic complications. Multiple studies have reported a high incidence of venous thromboembolism (VTE) in coronavirus-2019 disease (COVID-19) patients, in particular pulmonary thrombosis (79\%) [1-5]. Moreover, patients with severe COVID-19 manifested by acute respiratory distress syndrome (ARDS), have demonstrated extensive pulmonary

Lara Gianesello

gianesello.lara@libero.it

1 Emergency Department and Critical Care Area, Anesthesia and Intensive Care Unit, Santa Maria Annunziata Hospital, Bagno a Ripoli, Florence, Italy

2 Department of Anesthesia and Intensive Care, Orthopedic Anesthesia, University-Hospital Careggi, Largo Palagi, 1, 50139 Florence, Italy

3 Nephrology Unit Florence 1, Santa Maria Annunziata Hospital, Bagno a Ripoli, Florence, Italy

4 Department of Experimental and Clinical Medicine, University of Florence, Florence, Italy microvascular thromboses in available postmortem autopsies [6]; microvascular thrombosis may promote hypoxia through increased dead space leading to ventilation/perfusion (V/Q) mismatch or by promoting hypoxic vasoconstriction.

In the literature, a link between coagulation abnormalities and severe SARS-CoV-2 infection has been described [7] and several studies have found an association between increased plasma $\mathrm{D}$-dimer levels and unfavorable prognosis in COVID-19 patients [8]. However, in severe COVID-19, the pulmonary inflammation can cause fibrin deposits within alveoli and pulmonary extravascular space, as confirmed in autopsies series [9] and the lysis of these deposits could contribute to the rise of D-dimer which would be thus not specific of intravascular fibrin formation [10,11].

Patients with SARS-CoV-2 infection presented a peculiar form of coagulopathy, termed COVID-19 associated coagulopathy (CAC). CAC results from complex interactions between regulators of inflammation and coagulation; it is characterized by unique laboratory features different from either disseminated intravascular coagulation (DIC) and sepsis induced coagulopathy (SIC), such as the lack of consumption of platelets and coagulation factors. Increased fibrinogen, fibrin degradation products, prothrombin time (PT) and activated partial thromboplastin time (aPTT), have been described in patients with COVID-19 compared 
to healthy controls $[12,13]$. Despite their dissemination and ease of interpretation, these measurements focus on quantity rather than functionality of clotting components and provide information on clot formation, but do not address clot stability and dissolution.

Viscoelastic tests (VETs), such as rotational thromboelastometry (ROTEM, Tem Innovations, Munich, Germany), thromboelastography (TEG System, Haemonetics) and Quantra (Quantra System, HemoSonics LLC, Charlottesville, VA), are global hemostasis assays able to assess coagulation function, platelets and fibrinogen contribution to clot formation and fibrinolytic components [14-17]. These devices have been utilized in trauma and surgical care as an adjunct to conventional coagulation tests for guiding resuscitation and transfusion strategies $[18,19]$. In addition to the use in patients with a hypocoagulable state and bleeding tendency, VETs have been successfully used to detect hypercoagulable states in the setting of malignancy [20], trauma [21-23], intensive care unit (ICU) admission [24] and surgery $[25,26]$.

Recently, VETs appeared to play a role in assessing CAC. The purpose of this narrative review is to analyze the literature on the ability of VETs to evaluate the CAC, through possible answers to clinical questions.

\section{The viscoelastic tests: parameters and interpretation}

VETs (i.e. ROTEM, TEG and Quantra) are assays that measure changes in viscoelastic properties of whole blood. TEG and ROTEM are based on the same concept, described by Hartert [27], and measure the "shear modulus" of the clot, which represents its tendency to deform by the action of opposing forces. The shear modulus is defined as the ratio between shear stress and shear strain; it is not constant and changes along the process of clotting. In TEG a blood sample is injected in a cylindrical sample cup which rotates slowly through an area of $4.45^{\circ}$, every $5 \mathrm{~s}$, along the longitudinal axis; a free pin is immersed in the blood and, as long as the coagulation process begins, it detects the variation of strength between the pin and the cup wall. In ROTEM the mechanism is the opposite, as it is the pin which moves through an area of $4.75^{\circ}$, while the cup is fixed. Moreover, in TEG, the movement is detected by a torsion wide and not optical as in the ROTEM device; this makes the TEG 5000 system more sensitive to movement artifacts. Actually, the new TEG 6s device is using an ultrasound technology.

TEG and ROTEM explore the coagulation pathway using added activators and additives. In TEG the most widely activator used is Kaolin (K-TEG) to explore the intrinsic coagulation pathway. Its ROTEM equivalent is the INTEM, which uses ellagic acid and phospholipids as activators.
To explore the extrinsic pathway, the systems use activators such as tissue factor (TF) alone (extrinsically-activated assay, EXTEM) or in combination with Kaolin (RAPIDTEG). The contribution of fibrin on the clot amplitude is explored using additive platelets inhibitors [i.e. Abciximab for TEG (Functional Fibrinogen, FF assay) and cytochalasin D (FIBTEM assay) for ROTEM].

Based on time-resistance associations, TEG and ROTEM are characterized by tracings that represent a picture which starts from the beginning of clot formation throughout its lysis. In particular, TEG and ROTEM are able to detect both hypo- and hyperfunctional stages of the clotting process and are reliable rapid tests for the diagnosis of hyper or hypofibrinolysis [28-30]. In Fig. 1 the parameters obtained in TEG and in ROTEM and their meaning are shown.

Quantra System is based on technology called sonic estimation of elasticity via resonance, or sonorheometry [31, 32]. A multi-well plastic cartridge (Quantra QPlus) which includes four test channels allows to perform four parallel and independent measurements using different lyophilized reagent combinations in each channel. This technology is composed of three fundamental steps. First, an ultrasound pulse is transmitted in the blood sample to generate a shear wave, causing the sample to resonate. A series of ultrasound "tracking" pulses is then sent within the sample and the returning echoes are used to estimate the sample motion. The shear modulus of the sample is calculated by analyzing the sample motion pattern. This process is repeated every four seconds to form a signature curve that shows shear modulus vs. time. From this curve, the start of clot formation, or clot time, and the stiffness of the clot can be directly estimated. The combination of these two parameters provides information about the functional role of the coagulation factors, fibrinogen, and platelets in the sample. The Quantra system does not provide a TF activated clotting time (CT) and is limited to assess the intrinsic pathway (activation by kaolin). Furthermore, hyperfibrinolysis can only be detected in the Quantra system using a specific cartridge (QStat cartridge) [33]. No data are available whether the Quantra system can detect fibrinolysis shutdown which is an important issue in bacterial sepsis and COVID-19 [34-37].

The principal parameters evaluated in Quantra System are shown in the Fig. 2.

\section{Hypercoagulability and hypofibrinolysis in COVID-19 patients: two sides of the same coagulopathy?}

During infection, the coagulation cascade is activated as a physiological host defense to limit the spread of the pathogens [38]. In COVID-19 patients the severe inflammatory state can lead to severe derangement of hemostasis and 


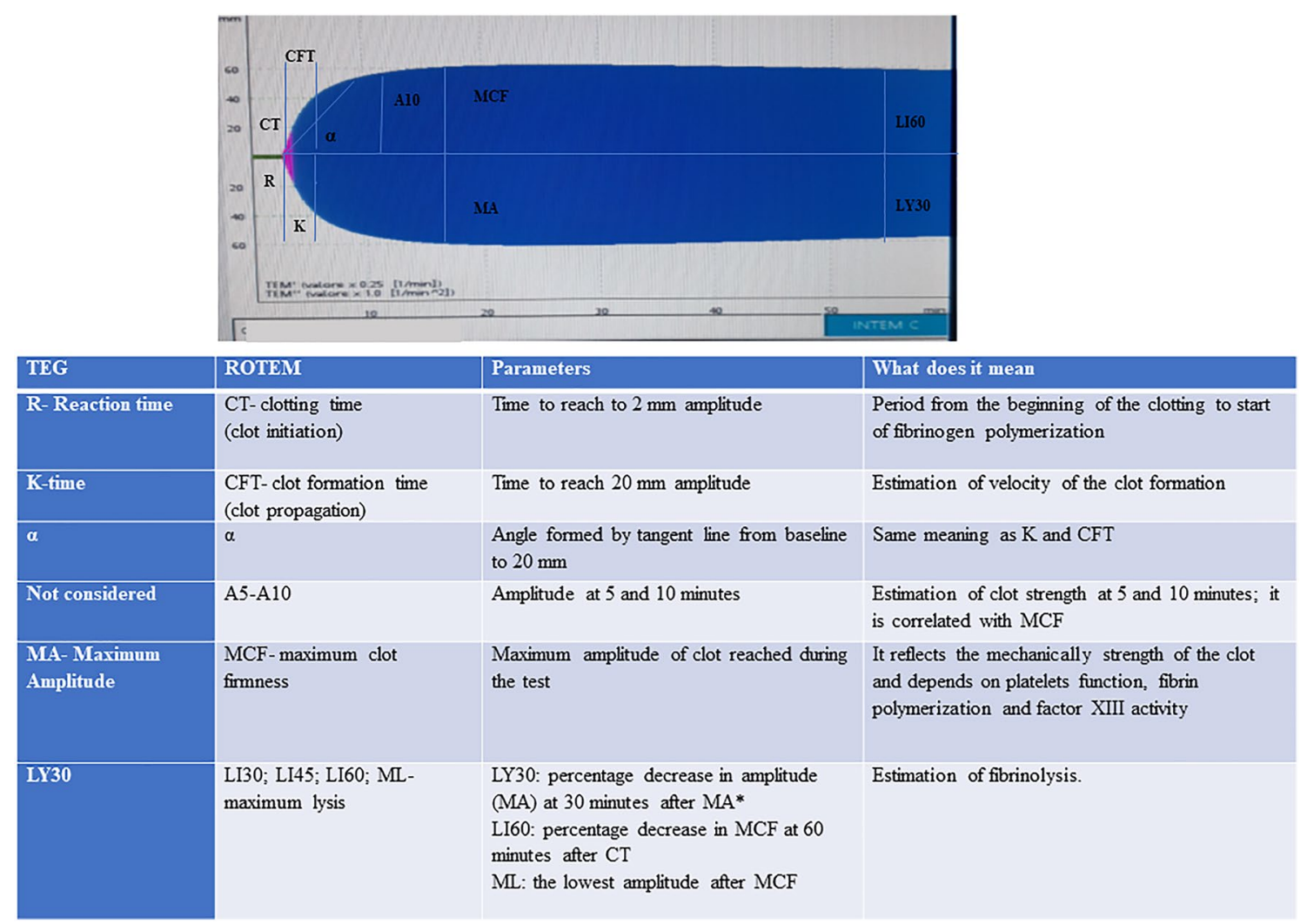

Fig. 1 TEG and ROTEM parameters and their significance. *TEG and ROTEM fibrinolysis parameters refer to different starting points. Whereas, ROTEM LI30, LI45 and LI60 are measured 30, 45 and $60 \mathrm{~min}$ after CT, TEG LY30 is measured $30 \mathrm{~min}$ after MA. Since
TEG time to MA is about $30 \mathrm{~min}, \mathrm{LY} 30$ is measured after about 60 min runtime as LI60 in ROTEM. In order to detect fibrinolysis shutdown, a runtime of 60 min (TEG LY30 or ROTEM LI60) is needed
Fig. 2 Quantra parameters and their significance

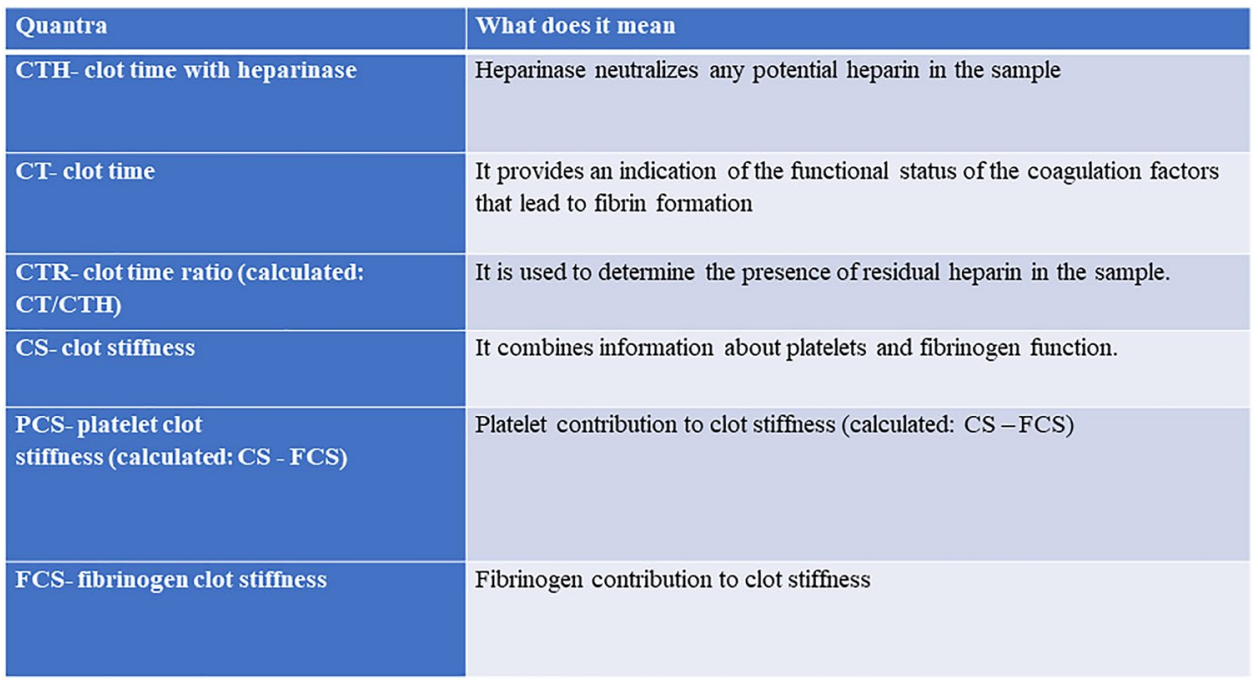

alteration of coagulation parameters [7, 13, 39], that has been demonstrated closely associated with worsening and death [7, 12].

In addition to the derangement of coagulation, endothelial activation/dysfunction contributes to the procoagulant state $[4,40]$ leading to pulmonary vasculature endotheliitis, microthrombosis and angiogenesis [6, 41, 42]. Here, TF expression by circulating monocytes and microparticles can be detected by ROTEM NATEM and interference 
with endogenous heparin-like effect can be eliminated by NAHEPTEM CT [34, 43, 44].

In COVID-19, simultaneously with the increase in procoagulant activity through TF pathway and endothelial activation, the plasmin activity is suppressed by the reduction in urokinase-type plasminogen activator (uPA) and the increase in plasminogen activator inhibitor-1 (PAI-1) levels. Inflammation promotes local release of tissue plasminogen activator (tPA) and PAI-1 from endothelial cells [45] and activated platelets may also release large amounts of PAI-1. Thus, increased PAI-1 levels may be responsible for hypofibrinolysis and fibrin persistence. Elevated PAI-1 levels and the associated hypofibrinolytic state were reported in patients with SARS-CoV [46], while recent characterizations of COVID-19 patients have suggested an impaired global fibrinolysis [36, 37, 46-49]. A recent study performed in severe COVID-19 patients has reported a significant hypercoagulability associated with hypofibrinolysis combined with high levels of PAI-1 and increased thrombin activatable fibrinolysis inhibitor (TAFI) activation [50]. Endothelial injury, hypercoagulability, hypofibrinolysis and fibrinolysis shutdown support the increased risk of pulmonary microthrombosis [51], the pathophysiological substratum of severe acute respiratory syndrome associated to SARS-CoV-2, and macrothrombosis (i.e. deep vein thrombosis and pulmonary embolism) [52-54].

The usefulness of VETs to assess hypercoagulability in COVID-19 infection has been evaluated by some studies (Table 1). Panigada et al. [55] demonstrated a higher velocity of clot formation (i.e. $\mathrm{R}$ and $\mathrm{K}$ value of TEG shorter) in $50 \%$ (R value) and 90\% (K value) of critically ill patients with COVID-19 than healthy population; moreover, maximum amplitude (MA) values were higher than reference population in $87 \%$ of COVID-19 patients. Similarly, Maatman et al. [56] showed a hypercoagulable feature (i.e. $\geq 2$ hypercoagulable TEG parameters) in $58 \%$ of severe COVID-19 patients. Using ROTEM device, Spiezia et al. [57] confirmed, in COVID-19 patients with acute respiratory failure, a profile of severe hypercoagulability rather than consumption coagulopathy. In particular, ROTEM profiles were characterized by significantly shorter clot formation time (CFT) in INTEM $(\mathrm{p}=0.0002)$ and EXTEM $(\mathrm{p}=0.01)$ and by a higher maximum clot firmness (MCF) in INTEM, EXTEM and FIBTEM $(\mathrm{p}<0.001)$ in patients than in healthy controls. Similarly, Kruse et al. [37] found substantial abnormalities in the ROTEM analysis in 40 critically ill COVID-19 patients; MCF in INTEM, EXTEM, FIBTEM and HEPTEM was markedly elevated in the entire cohort compared to reference values with median values of $74 \mathrm{~mm}, 75 \mathrm{~mm}, 34.5 \mathrm{~mm}$ and $73 \mathrm{~mm}$, respectively. In the same line, Pavoni et al. [58] showed that in severe COVID-19 pneumonia hypercoagulability is detectable, characterized by an acceleration of the propagation phase of blood clot formation and significantly increased clot strength; this hypercoagulable state persists during the first days after ICU admission, and it decreases over time. Recently, Hulshof et al. [59] observed in 36 critically COVID-19 patients a persistent increase in MCF that was more prominent in FIBTEM compared to EXTEM, highlighting an hypercoagulable state which was largely dependent on fibrinogen value. Moreover, the hypercoagulability associated to a severe hypofibrinolysis persisted at least six weeks despite anticoagulation.

Using Quantra as viscoelastic test, Ranucci et al. [60] confirmed that COVID-19 patients with ARDS had a procoagulant profile characterized by an increased clot strength (CS), with platelet and fibrinogen contribution to CS. Furthermore, after increasing the thromboprophylaxis these values decreased significantly. Similarly, Van der Linden et al. [61] found a reduction in fibrinogen-dependent hypercoagulation indicated by ROTEM analysis in ICU-treated COVID-19 patients after enhanced anticoagulation strategy.

Other studies confirmed that critically ill patients with COVID-19 have hypercoagulable viscoelastic profiles with an elevated MA or MCF, suggesting a significant fibrinogen and platelet effect on clot strength [62, 63].

Another important key contributor to COVID-19 thrombosis together with a hypercoagulable state, is the presence of hypofibrinolysis or fibrinolysis shutdown. Five [36, 37, $49,64,65]$ studies have highlighted the ability of VETs to diagnose the presence of severely impaired fibrinolysis rapidly at the bedside in critically ill COVID-19 patients. Using ROTEM parameters, a hypofibrinolytic state in COVID-19 patients, defined as lysis index at 60 min after coagulation time (LI60) in EXTEM of 99 (97-100\%), was found by Ibanez et al. [64]. Kruse et al. [37] confirmed these results and found the maximum lysis (ML) in both EXTEM and INTEM to be markedly below normal value in 40 critically ill COVID-19 patients. Of note, the fibrinolysis shutdown in combination with increased D-dimer was the best predictor of thromboembolic events in critically ill COVID19 patients. Similarly, Creel-Bulos et al. [36] investigated a population of 25 critically ill patients with COVID-19 and found the presence of fibrinolysis shutdown at ROTEM analysis in 11 patients (44\%); the authors demonstrated again that fibrinolysis shutdown was a good predictor of thrombosis in severe COVID-19. Wright et al. [49] reported a fibrinolysis shutdown, evidenced by a complete shutdown of fibrinolysis at $30 \mathrm{~min}$ after maximum amplitude (LY30 on TEG) in 57\% of a group of critically ill patients. Moreover, marked D-dimer elevation and TEG LY30 levels of $0 \%$ were seen in patient samples drawn more than two weeks of ICU stay, so suggesting a prolonged hypofibrinolytic state. In the same line, Pavoni et al. [65] comparing ROTEM analysis of critically ill patients with pneumonia not due to COVID19 and due to COVID-19, observed a higher incidence of 
Table 1 A Summary of published studies on use of TEG and ROTEM in COVID-19 patients; B summary of published studies on use of Quantra System in COVID-19 patients

\begin{tabular}{|c|c|c|c|c|c|c|c|c|}
\hline \multicolumn{9}{|l|}{$\mathrm{A}$} \\
\hline Study & Type VET & Population & n. patients & $\begin{array}{l}\mathrm{R}(\min ) / \mathrm{CT} \\
\text { (s) EXTEM }\end{array}$ & $\begin{array}{l}\text { K (min)/CFT } \\
\text { (s) EXTEM }\end{array}$ & Angle K $\left(^{\circ}\right)$ & $\begin{array}{l}\text { MA (mm)/ } \\
\text { MCF (mm) } \\
\text { EXTEM }\end{array}$ & $\begin{array}{l}\text { LY30 - LY60 } \\
(\%) / L I 30-\text { LI60 } \\
(\%)-\text { ML }(\%) \\
\text { EXTEM }\end{array}$ \\
\hline Wright [49] & TEG & ICU & 44 & $5.8(4.8-8.6)$ & N/A & $71(66-74)$ & $73(67-77)$ & $\begin{array}{r}0(0-0.4) \\
(\mathrm{LY} 30)\end{array}$ \\
\hline Panigada [55] & TEG 5000 & ICU & 24 & $6.3(3.0-11.9)$ & $1.5(0.8-2.9)$ & $\begin{array}{l}69.4(51.1- \\
78.5)\end{array}$ & $79.1(58-92)$ & $\begin{array}{c}7.8(0-54.3) \\
(\text { LY30) }\end{array}$ \\
\hline Maatman [56] & TEG 5000 & ICU & 12 & $4.8 \pm 1.1$ & $1.4 \pm 1.1$ & $69.6 \pm 10.9$ & $70.8 \pm 8.5$ & $0.8 \pm 0.9(\mathrm{LY} 30)$ \\
\hline Spiezia [57] & ROTEM delta & ICU & 22 & $75 \pm 16$ & $66 \pm 20$ & N/A & $69 \pm 6$ & $1 \pm 3(\mathrm{ML})$ \\
\hline Kruse [37] & $\begin{array}{c}\text { ROTEM } \\
\text { sigma }\end{array}$ & ICU & 40 & $86(69.5-99.8)$ & $46.5(40-60.5)$ & N/A & 75 (70.3-78) & $\begin{array}{l}3(1.3-5.8) \\
(\mathrm{ML})\end{array}$ \\
\hline Pavoni [58] & $\begin{array}{c}\text { ROTEM } \\
\text { sigma }\end{array}$ & ICU & 40 & $78.3 \pm 17.2$ & $41.6 \pm 11.4$ & N/A & $76.6 \pm 6.4$ & $9.4 \pm 6.6(\mathrm{ML})$ \\
\hline $\begin{array}{l}\text { Yuriditsky } \\
\text { [62] }\end{array}$ & TEG 5000 & ICU & 64 & $6.4(4.8-9.17)$ & $1(0.8-1.3)$ & $\begin{array}{l}75.3(69.9- \\
78.4)\end{array}$ & $\begin{array}{l}72.8(67.9- \\
77.6)\end{array}$ & $\begin{array}{l}0.10(0.00- \\
1.20)(\mathrm{LY} 30)\end{array}$ \\
\hline $\begin{array}{l}\text { Wallance } \\
\text { Collett [63] }\end{array}$ & $\begin{array}{c}\text { ROTEM } \\
\text { sigma }\end{array}$ & ICU & 6 & N/A & $48.5(41-60.5)$ & N/A & $\begin{array}{l}74.5(72.5- \\
79.5)\end{array}$ & $\begin{array}{l}1.5(1-4.25) \\
(\mathrm{ML})\end{array}$ \\
\hline Ibanez [64] & $\begin{array}{c}\text { ROTEM } \\
\text { sigma }\end{array}$ & ICU & 19 & $78(63-91)$ & $41(40-53)$ & N/A & $74(71-76)$ & $\begin{array}{l}100(100-100) \\
\text { (LY30) }\end{array}$ \\
\hline Pavoni [65] & $\begin{array}{c}\text { ROTEM } \\
\text { sigma }\end{array}$ & ICU & 20 & $62.4 \pm 9.6$ & $47.4 \pm 15.2$ & N/A & $74.3 \pm 3.2$ & $9.5 \pm 5.0(\mathrm{ML})$ \\
\hline Sadd [66] & TEG & ICU & 10 & $4.45(3.6-5.8)$ & $1(1-1.3)$ & $\begin{array}{l}78.25(75.1- \\
78.7)\end{array}$ & $\begin{array}{l}71.95(68.5- \\
74.5)\end{array}$ & $\begin{array}{l}0.75(0-2.6) \\
(\text { LY30) }\end{array}$ \\
\hline Bocci [67] & TEG $6 \mathrm{~s}$ & ICU & 40 & $7.1(5.2-8.1)$ & $1.1(0.9-1.5)$ & $\begin{array}{l}74.9(70.9- \\
77.5)\end{array}$ & $\begin{array}{l}69.8(66.3- \\
71.3)\end{array}$ & $0(0-0)(\mathrm{LY} 30)$ \\
\hline \multirow[t]{2}{*}{ Tsantes [68] } & ROTEM & ICU & 11 & $73.5 \pm 15.5$ & $40.7 \pm 13.0^{\S}$ & N/A & $75.7 \pm 5.0^{\S}$ & $\begin{array}{c}99.5 \pm 1.0 \\
(\text { LI60)* }\end{array}$ \\
\hline & & Ward & 21 & $73.5 \pm 12.0$ & $59.5 \pm 24.9$ & N/A & $72.4 \pm 4.0$ & $\begin{array}{l}96.3 \pm 2.9 \\
(\text { LI60) }\end{array}$ \\
\hline Mortus [78] & TEG & ICU & 21 & $10 \pm 11$ & N/A & $60 \pm 23$ & $67 \pm 17$ & $0.9 \pm 1.8(\mathrm{LY} 30)$ \\
\hline Shah [79] & TEG $6 \mathrm{~s}$ & ICU & 187 & $7.37 \pm 2.45$ & N/A & $75.7 \pm 3.4$ & $69.3 \pm 2.26$ & $\begin{array}{l}0.00(0.00- \\
0.05)(\mathrm{LY} 30)\end{array}$ \\
\hline Stattin [80] & TEG $6 \mathrm{~s}$ & ICU & 21 & $7.3(6.7-8.2)$ & $6.9(6.7-8.2)$ & $76(75-78)$ & $69(68-71)$ & $\begin{array}{l}0.0(0.0-0.2) \\
(\text { LY30) }\end{array}$ \\
\hline $\begin{array}{l}\text { van } \\
\text { Veenendaal } \\
{[81]}\end{array}$ & $\begin{array}{l}\text { ROTEM } \\
\text { sigma }\end{array}$ & ICU & 47 & $85.5 \pm 20.6$ & $45.3 \pm 10.0$ & N/A & $77.3 \pm 4.1$ & N/A \\
\hline Salem [84] & TEG $6 \mathrm{~s}$ & ICU & 52 & $8.1(6.7-10.6)$ & $1.3(1.2-1.9)$ & $\begin{array}{l}72.1(67.2- \\
74.4)\end{array}$ & $\begin{array}{l}65.8(59.6- \\
68.7)\end{array}$ & $\begin{array}{l}0.0(0.0-0.1) \\
(\text { LY30) }\end{array}$ \\
\hline Hoechter [96] & ROTEM delta & ICU & 22 & $62(56-68)$ & 93 (55-97) & N/A & $65(63-70)$ & $\begin{array}{l}6.5(4.5-9.0) \\
(\mathrm{ML})\end{array}$ \\
\hline Spiezia [97] & $\begin{array}{c}\text { ROTEM } \\
\text { sigma }\end{array}$ & Ward & 56 & $66 \pm 9$ & $48 \pm 15$ & N/A & $71 \pm 6$ & $\begin{array}{l}\text { 1-2 (Range) } \\
\text { (ML) }\end{array}$ \\
\hline Roh [98] & ROTEM & ICU & 30 & $108 \pm 54$ & N/A & N/A & $75 \pm 5$ & N/A \\
\hline \multirow[t]{2}{*}{ Boscolo [106] } & ROTEM & ICU & 32 & $74(64-88)^{*}$ & $60(48-80)^{*}$ & N/A & $71(65-75)$ & N/A \\
\hline & & Ward & 32 & $65(61-72)$ & $43(38-56)$ & & $72(68-75)$ & \\
\hline \multirow[t]{2}{*}{$\begin{array}{c}\text { Almskog } \\
\text { [107] }\end{array}$} & $\begin{array}{l}\text { ROTEM } \\
\text { sigma }\end{array}$ & Regular ward & 40 & $70(61-75)^{*}$ & $49(43-63)$ & N/A & $70(66-73)^{\S}$ & $\begin{array}{l}100(100-100) \\
(\text { LI30) }\end{array}$ \\
\hline & & $\begin{array}{l}\text { Specialized } \\
\text { ward (NIV) }\end{array}$ & 20 & $90(78-108)$ & $46(42-55)$ & N/A & $76(71-77)$ & $\begin{array}{l}100(100-100) \\
\text { (LI30) }\end{array}$ \\
\hline Blasi [108] & $\begin{array}{c}\text { ROTEM } \\
\text { sigma }\end{array}$ & ICU & 12 & $70.5(66.3-75)$ & N/A & N/A & $71(67-75.8)$ & $\begin{array}{l}100(99.3-100) \\
(\mathrm{LY} 60)^{*}\end{array}$ \\
\hline
\end{tabular}


Table 1 (continued)

\begin{tabular}{|c|c|c|c|c|c|c|c|c|c|}
\hline \multicolumn{10}{|l|}{ B } \\
\hline Study & Type VET & Population & n. patients & CT & $\mathrm{CTH}$ & CTR & $\mathrm{CS}$ & PCS & FCS \\
\hline Ranucci [60] & Quantra & ICU & 16 & $\begin{array}{l}139(133- \\
155)\end{array}$ & N/A & N/A & $55(35-63)$ & $43(24-45)$ & $12(6-13.5)$ \\
\hline Masi [99] & Quantra & ICU & 17 & $152(30-171)$ & $\begin{array}{c}130(117- \\
152)\end{array}$ & $1.1(1.1-1.3)$ & $\begin{array}{l}49.9 \\
\quad(38.5-68)\end{array}$ & $\begin{array}{l}38.5(28.85- \\
51.2)\end{array}$ & $\begin{array}{l}12.8(6.35- \\
20.85)\end{array}$ \\
\hline
\end{tabular}

$I C U$ intensive care unit, $N I V$ non-invasive ventilation, $V E T$ viscoelastic test, TEG thromboelastography, ROTEM rotational thromboelastometry, $C T$ clotting time, $R$ reaction time, $K$ time, $C F T$ clot formation time, $M A$ maximum amplitude, $M C F$ maximum clot formation, $L Y 30$ the decrease in clot firmness in percentage of maximum amplitude (MA) $30 \mathrm{~min}$ after MA, LI30-LI60 the residual clot firmness in percentage of maximum clot firmness $30 \mathrm{~min}$ (LI30) or $60 \mathrm{~min}$ (LI60) after CT, $M L$ maximum lysis, CTH clot time with heparinase, CTR clot time ratio, CS clot stiffness, $P C S$ platelet clot stiffness, $F C S$ fibrinogen clot stiffness, N/A not available

${ }^{*} \mathrm{p}<0.001,{ }^{\S} \mathrm{p}<0.05$

fibrinolysis shutdown in $50 \%$ samples from patients with COVID-19 obtained 5 days after ICU admission.

Finally, three studies evaluated the impact of anticoagulation on VETs parameters. Sadd et al. [66] confirmed the hypercoagulability and a decreased or absent fibrinolysis by TEG in 10 ARDS critically ill patients with COVID19 infection; in 4 of 10 patients who received thrombolytic therapy repeated TEG demonstrated improvement in coagulation index and lysis at 30 min reflecting reduced hypercoagulability and increased fibrinolysis. On the contrary, Bocci et al. [67] in 40 consecutive SARS-CoV-2 patients admitted to the ICU, found that TEG parameters did not significantly differ after a week of full dose systemic anticoagulation. In the same line, Tsantes et al. [68], with ROTEM device, demonstrated that critically ill COVID-19 patients had a hypercoagulability and fibrinolysis shutdown, despite the administration of therapeutic anticoagulant treatment.

In conclusion, from the current literature data, it emerges that, in COVID-19 patients, the use of VETs provides more comprehensive assessment of CAC than standard coagulation parameters and may identify the two sides of CAC such as hypercoagulability and hypofibrinolysis.

\section{Can VETs predict thrombotic complications in COVID-19 patients?}

VETs have proved be able to predict the risk of developing VTE in trauma and orthopedic settings $[69,70]$. In particular, in trauma population, a hypercoagulable TEG profile, based on higher MA parameter, can predict VTE [71, 72]. The predictive value of ROTEM for thrombosis has also been demonstrated in cardiac and non-cardiac surgery as well as in cirrhosis and liver transplantation [73-77].

In COVID-19 population, ten studies evaluated the predictivity of VETs for VTE diagnosis, based on hypercoagulable state and hypofibrinolysis. In Table 2 viscoelastic parameters derived from seven of ten studies analyzed are reported.

Wright et al. [49] showed that a fibrinolysis shutdown predicts VTE (area under the receiver operating characteristics curve (ROC) [AUC], 0.74 [95\% CI, 0.58 to 0.9]; $\mathrm{p}=0.021$ ) in critically ill patients with COVID-19. In particular, a combination score with TEG LY30 of $0 \%$ and a D-dimer of $>2.600$ FEU was associated with an increased risk of VTE $(\mathrm{p}=0.008)$. In patients presenting neither elevated D-dimer nor fibrinolysis shutdown, the incidence of VTE was $0 \%$; in contrast, in patients presenting elevated D-dimer and fibrinolysis shutdown, the incidence of VTE was $50 \%$. Similar to this study, Kruse et al. [37] evidenced that hypofibrinolysis is an important contributor to the hypercoagulable state in COVID-19 patients. The authors demonstrated that ROC AUC to predict thrombosis for maximum D-dimer was 0.78 and for EXTEM ML was 0.8 , but could be increased to 0.92 by the combination of maximum D-dimer and EXTEM ML. The optimum cut-off value for "max D-dimer (mg/l) - EXTEM ML (\% of MCF at $60 \mathrm{~min})$ " was 3.7. For standardized interpretation, the formula " $\max$ D-dimer (in mg/l) - 100 + EXTEM LI60 (in \% of MCF)" might be preferable because this clearly defines the measurement time for fibrinolysis.

In a case series of critically ill COVID-19 patients [36], thrombotic events were found in $73 \%$ of cases with fibrinolytic shutdown and $89 \%$ of patients with thrombotic events met the criteria for fibrinolysis shutdown. Similarly, Mortus et al. [78] described in patients with high thrombotic events group ( $\geq 2$ thrombotic events) a greater innate TEG MA than in the low events group (0-1 thrombotic events). In particular, elevated MA was observed in 10 patients $(100 \%)$ in the high events group vs. 5 patients $(45 \%)$ in the low events group. However, the sample size of this study was very small (21 patients). In the same way, Nougier et al. [50] using 
Table 2 Summary of published studies on use of viscoelastic tests (i.e. TEG and ROTEM) in COVID-19 patients with thrombotic complications (TR) vs. non thrombotic (non-TR) complications or stratified by clotting index (CI)

\begin{tabular}{|c|c|c|c|c|c|c|c|c|}
\hline Study & Type VET & Population (n) & $\begin{array}{l}\text { TR inci- } \\
\text { dence } \\
(\%)\end{array}$ & $\begin{array}{l}\mathrm{R}(\min ) / \mathrm{CT}(\mathrm{s}) \\
\text { EXTEM }\end{array}$ & $\begin{array}{l}\mathrm{K}(\min ) / \mathrm{CFT} \\
\text { (s) EXTEM }\end{array}$ & Angle $\mathrm{K}\left({ }^{\circ}\right)$ & $\begin{array}{l}\text { MA (mm)/ } \\
\operatorname{MCF}(\mathrm{mm}) \\
\operatorname{EXTEM}\end{array}$ & $\begin{array}{l}\text { LY30 (\%)/ } \\
\text { LI30-LI60 } \\
(\%)-\text { ML (\%) } \\
\text { EXTEM }\end{array}$ \\
\hline \multirow[t]{2}{*}{ Kruse [37] } & $\begin{array}{c}\text { ROTEM } \\
\text { sigma }\end{array}$ & ICU TR & 23 & $84(69-96)$ & $47(40-61)$ & N/A & $75(69-78)$ & $3(0-5)(\mathrm{ML})^{*}$ \\
\hline & & ICU non-TR & 17 & $\begin{array}{c}86(70.5- \\
107.5)\end{array}$ & $45(40.5-56.5)$ & N/A & $76(72.5-78.5)$ & $5(3.5-8)(\mathrm{ML})$ \\
\hline \multirow[t]{2}{*}{$\begin{array}{l}\text { Yuriditsky } \\
\text { [62] }\end{array}$} & TEG 5000 & $\begin{array}{c}\text { ICU CI }>3 \\
(32)\end{array}$ & 11 & $\begin{array}{c}5.25(4.50- \\
7.62)^{\S}\end{array}$ & $\begin{array}{l}0.80(0.80- \\
1.00)^{*}\end{array}$ & $\begin{array}{c}77.3(75.4- \\
79.0)^{*}\end{array}$ & $\begin{array}{l}76.2(72.1- \\
81.0)^{*}\end{array}$ & $\begin{array}{c}0(0-1.38) \\
\quad(\text { LY30) }\end{array}$ \\
\hline & & $\begin{array}{c}\text { ICU CI }<3 \\
(32)\end{array}$ & 9 & $7.7(5.52-9.35)$ & $\begin{array}{l}1.25(1.02- \\
1.67)\end{array}$ & $\begin{array}{l}70.2(63.7- \\
75.1)\end{array}$ & $\begin{array}{l}68.8(62.0- \\
74.3)\end{array}$ & $\begin{array}{l}0.10(0-1.15) \\
(\text { LY30) }\end{array}$ \\
\hline \multirow[t]{2}{*}{ Mortus [78] } & TEG & $\begin{array}{l}\text { ICU high TR } \\
\text { (10) }\end{array}$ & 62 & $7.1 \pm 5^{\circ}$ & N/A & $68 \pm 16^{\circ}$ & $75 \pm 7^{\circ}$ & $0.6 \pm 1(\mathrm{LY} 30)^{\circ}$ \\
\hline & & $\begin{array}{l}\text { ICU low TR } \\
\text { (11) }\end{array}$ & & $13 \pm 14$ & N/A & $52 \pm 27$ & $61 \pm 21$ & $3.5 \pm 4.6(\mathrm{LY} 30)$ \\
\hline \multirow[t]{2}{*}{ Shah [79] } & TEG $6 \mathrm{~s}$ & ICU TR (81) & 43.3 & $7.7 \pm 1.87$ & N/A & $75.5 \pm 3.5$ & $69.3 \pm 1.7$ & $\begin{array}{l}0.00(0.00-0.00) \\
\quad(\mathrm{ML})\end{array}$ \\
\hline & & $\begin{array}{l}\text { ICU non-TR } \\
\quad(106)\end{array}$ & & $6.86 \pm 3.22$ & N/A & $75.7 \pm 3.4$ & $69.4 \pm 3.06$ & $\begin{array}{l}0.00(0.00-0.48) \\
\quad(\mathrm{ML})\end{array}$ \\
\hline \multirow[t]{2}{*}{ Stattin [80] } & TEG $6 \mathrm{~s}$ & ICU TR (5) & 16.1 & $6.2(5.3-7.7)$ & $6.5(5.4-8.5)$ & 76 (74-77) & $70(68-70)$ & $\begin{array}{l}0.0(0.0-0.0) \\
(\text { LY30) }\end{array}$ \\
\hline & & $\begin{array}{l}\text { ICU non-TR } \\
\quad(26)\end{array}$ & & $7.2(6.4-8.2)$ & $7.0(6.2-7.7)$ & $77(76-79)$ & $70(69-73)$ & $\begin{array}{l}0.0(0.0-0.2) \\
\quad(\text { LY30) }\end{array}$ \\
\hline \multirow{2}{*}{$\begin{array}{l}\text { van } \\
\text { Veenendaal } \\
{[81]}\end{array}$} & $\begin{array}{c}\text { ROTEM } \\
\text { sigma }\end{array}$ & ICU TR (10) & 21.3 & $95.7 \pm 17.4$ & $54.1 \pm 8.4^{\S}$ & N/A & $75 \pm 5.9^{\S}$ & N/A \\
\hline & & $\begin{array}{l}\text { ICU non-TR } \\
\text { (37) }\end{array}$ & & $82.8 \pm 20.8$ & $42.9 \pm 9.2$ & N/A & $77.9 \pm 3.3$ & N/A \\
\hline \multirow[t]{2}{*}{ Salem [84] } & TEG $6 \mathrm{~s}$ & ICU TR (14) & 26.9 & $7.7(7.3-10.8)$ & $1.3(1.2-1.9)$ & $73.2(68-74.8)$ & $\begin{array}{l}66.7(61.4- \\
68.1)\end{array}$ & $\begin{array}{l}0.0(0.0-0.0) \\
(\mathrm{LY} 30)\end{array}$ \\
\hline & & $\begin{array}{l}\text { ICU non-TR } \\
\text { (38) }\end{array}$ & & $8.5(6.2-10.8)$ & $1.5(1.2-1.9)$ & $70.9(67-74.3)$ & $\begin{array}{l}65.2(59.4- \\
68.9)\end{array}$ & $\begin{array}{l}0.0(0.0-0.2) \\
(\text { LY30) }\end{array}$ \\
\hline
\end{tabular}

ICU intensive care unit, VET viscoelastic test, TEG thromboelastography, ROTEM rotational thromboelastometry, $C T$ clotting time, $R$ reaction time, $K$ time, $C F T$ clot formation time, $M A$ maximum amplitude, $M C F$ maximum clot formation, $L Y 30$ the decrease in clot firmness in percentage of maximum amplitude (MA) $30 \mathrm{~min}$ after MA, LI30-LI60 the residual clot firmness in percentage of maximum clot firmness 30 min (LI30) or $60 \mathrm{~min}$ (LI60) after CT, $M L$ maximum lysis, $C I$ clotting index, N/A not available

${ }^{*} \mathrm{p}<0.001,{ }^{\circ} \mathrm{p}<0.01,{ }^{\S} \mathrm{p}<0.05$

EXTEM reagent of ROTEM delta device with the addition of $0.625 \mu \mathrm{g} / \mathrm{ml}$ tPA (tPATEM), reported decreased clot lysis in COVID-19 patients admitted to ICU and internal medical department; this fibrinolysis resistance was more evident in patients who presented a thrombotic event compared with event-free patients.

On the other hand, Shah et al. [79] confirmed that TEG has hypercoagulable profile characterized by $\alpha$ angle and MA values at or above the upper limits of the normal reference range and extremely low LY30; however, the authors observed no differences in these parameters between patients who developed thrombotic complications and those who did not. In the same line, Stattin et al. [80], in 31 critically ill patients, demonstrated no difference in MA between patients with or without thromboembolic events. Notably, van Veenendaal et al. [81] reported that ROTEM confirmed the hypercoagulable state in COVID-19, but hypercoagulability (increased clot firmness) did not predict thrombosis. However, the authors did not include fibrinolysis parameter in their analysis. Accordingly, their results were in-line with Kruse et al. [37] showing that clot firmness was increased in all critically COVID-19 patients, but only fibrinolysis shutdown and D-dimer were highly predictive for thrombosis, particularly if used in combination. Furthermore, in the van Veenendaal et al.'s study [81] clot firmness was lower and CFT longer in patients with VTE; the authors concluded 
that heparin could have influenced ROTEM results. Actually, this results do not appear surprising: whereas hypercoagulability (increased clot firmness) has been shown to be predictive for thromboembolic events in several clinical settings [69-77], active thrombosis can result in decreased clot firmness in EXTEM and FIBTEM due to the consumption of platelets and fibrinogen. Accordingly, an increase in D-dimer/fibrinogen ratio has been reported as a marker of thrombosis and ischemic stroke [82, 83]. Alike, Salem et al. [84], using TEG device, did not find a significant association between a hypercoagulable state and thromboembolic events. Similarly, Yuriditsky et al. [62], demonstrated no significant differences in ROTEM parameters between critically ill COVID-19 patients with confirmed VTE and those without VTE. Finally, a small recent study [56] that evaluated twelve severe COVID-19 patients, documented the development of VTE in three patients with a hypercoagulable TEG; however, one patient with normal TEG parameters developed VTE.

In conclusion, VETs demonstrate a hypercoagulable state with increased clot firmness in hospitalized COVID-19 patients. However, hypercoagulability alone is not predictive for thrombotic events in critically ill COVID-19 patients. Here, fibrinolysis shutdown in ROTEM or TEG, particularly in combination with increased D-dimer, is highly predictive for thromboembolic events [37, 49]. Moreover, the interim analysis of the multiplatform randomized clinical trials (ACTIV-4a and REMAP-CAP and ATTACC [Antithrombotic Therapy to Ameliorate Complications of COVID19]) [85] suggests that patients with moderate COVID-19 (hospitalized but not requiring organ support) may benefit from therapeutic anticoagulation (odds ratio for survival or reduced requirement for organ support, 1.57 (95\% CI, 1.14 to 2.19 ), but critically ill patients with severe COVID-19 show an increased incidence of major bleeding (3.7\% versus $1.8 \%$ ) and mortality (OR for survival and decreased need for organ support, $0.76,95 \%$ CI, 0.6 to 0.97 ). Therefore, the anticoagulation concept in COVID-19 might change from an escalating (intensified anticoagulation in critically ill COVID-19 patients) to a deescalating concept (decrease anticoagulation from therapeutic to prophylactic dose in critically ill COVID-19 patients presenting a decrease in clot firmness due to liver failure, bacterial superinfection, and/or DIC). Here, VTEs might help identifying COVID19 patients with decreased need for anticoagulation (e.g., EXTEM MCF $<68 \mathrm{~mm}$ and FIBTEM MCF $<24 \mathrm{~mm}$ ) or even increased risk of bleeding (e.g., EXTEM MCF $<50 \mathrm{~mm}$ and FIBTEM MCF < $14 \mathrm{~mm}$ ) [86-90]. This could hypothesize a role of VETs not only in the identification of thromboembolic risk, but also in its treatment.

\section{Is CAC different from hypercoagulability caused by bacterial agents?}

Epidemiological studies indicated that severe sepsis, correlated to bacterial pneumonia, is associated with an increased risk to develop arterial and venous thrombosis, due to activation of the clotting system and inhibition of anticoagulant factors [91, 92]. The linear progression from SIC to DIC usually seen in septic patients [93], does not necessarily occur in COVID-19 patients, in whom it seems to be present a peculiar form of coagulopathy, termed as CAC. In contrast to CAC, bacterial sepsis is associated with early hypocoagulability and platelet dysfunction which also predicts mortality in bacterial sepsis $[94,95]$.

Using VETs, five studies with ROTEM [65, 68, 96-98] and one with Quantra [99], compared the grading of hypercoagulability of critically ill patients with acute respiratory failure due to infection from SARS-CoV-2 and other pathogens; one study instead compared noncritical patients [97]. Hoechter et al. [96] demonstrated, with ROTEM, that patients with COVID-19 pneumonia presented significantly shorter time from initial clot formation up to a clot amplitude of $20 \mathrm{~mm}$ (Time-to-Twenty, TT20) compared to non-COVID-19 pneumonia (143 vs. $155, \mathrm{p}=0.047)$, whereas EXTEM CT and EXTEM CFT tended to be shorter in the COVID-19 patients (CT: 62 vs. $70, p=0.09$, CFT: 93 vs. 84, $p=0.301$ ). Likewise, Pavoni et al. [65] reported a shorter clot propagation in COVID19 compared to non-COVID-19 patients (CFT $47.4 \pm 15.2$ vs. $124 \pm 31, \mathrm{p}<0.0001)$; moreover, COVID-19 patients had a significantly higher clotting stabilization (i.e. MCF in EXTEM) than non-COVID-19 that persists over time. In Tsantes et al.'s study [68] a greater hypercoagulable state was detected in COVID-19 ICU patients than in nonCOVID-19 ICU patients based on A10 and MCF parameters. Similarly, using the Quantra System, Masi et al. [99] observed that unlike non COVID-19 ARDS, COVID-19 ARDS was associated with a significant increase of clot stiffness and platelet and fibrinogen contribution to clot stiffness. Furthermore, similar results were reported in patients with acute COVID-19 pneumonia compared to other pneumonia, admitted to medical wards [97], even if alterations of ROTEM analysis were less marked. This indicates that the hypercoagulability of the SARS-CoV-2 infection is present even in a mild disease. Different results were reported by Roh et al. [98] that found slower coagulation kinetics on ROTEM testing in COVID-19 patients compared to matched non COVID-19 surgical patients in both the extrinsic [EXTEM CT 108 (54) vs. 57 (31), $\mathrm{p}<0.0001$ )] and intrinsic [INTEM CT 205 (65) vs. 169 (57), $\mathrm{p}=0.01$ ] pathways; however, similarly to previous studies $[65,96,97]$ a significantly higher clot strength 
Table 3 A Summary of studies on use of TEG and ROTEM in COVID-19 patients compared to non-COVID-19 patients; B summary of studies on use of Quantra System in COVID-19 patients

\begin{tabular}{|c|c|c|c|c|c|c|c|c|c|c|}
\hline \multicolumn{11}{|l|}{$\mathrm{A}$} \\
\hline Study & \multicolumn{2}{|c|}{ Type VET } & \multicolumn{2}{|c|}{ Population } & n. patients & $\begin{array}{l}\mathrm{R}(\min ) / \mathrm{CT} \\
\text { (s) EXTEM }\end{array}$ & $\begin{array}{l}\mathrm{K}(\min ) / \mathrm{CFT} \\
\text { (s) EXTEM }\end{array}$ & $\begin{array}{l}\text { MA (mm)/MCF } \\
(\mathrm{mm}) \text { EXTEM }\end{array}$ & \multicolumn{2}{|c|}{$\begin{array}{l}\text { LY30 - LY60 (\%)/ LI30/ } \\
\text { LI60 (\%)-ML (\%) } \\
\text { EXTEM }\end{array}$} \\
\hline \multirow[t]{2}{*}{ Pavoni [65] } & \multirow{2}{*}{\multicolumn{2}{|c|}{ ROTEM sigma }} & \multicolumn{2}{|c|}{ ICU COVID-19 } & 20 & $62.4 \pm 9.6$ & $47.4 \pm 15.2^{\circ}$ & $74.3 \pm 3.2^{\circ}$ & \multicolumn{2}{|c|}{$9.5 \pm 5.0(\mathrm{ML})$} \\
\hline & & & \multicolumn{2}{|c|}{ ICU non-COVID-19 } & 25 & $59 \pm 6.1$ & $124 \pm 31$ & $60.4 \pm 5.6$ & \multicolumn{2}{|c|}{$7.2 \pm 3.0(\mathrm{ML})$} \\
\hline \multirow[t]{2}{*}{ Tsantes [68] } & \multicolumn{2}{|c|}{ ROTEM } & \multicolumn{2}{|c|}{ ICU COVID-19 } & 11 & $73.5 \pm 15.5$ & $40.7 \pm 13.0$ & $75.7 \pm 5.0^{\S}$ & \multicolumn{2}{|c|}{$99.5 \pm 1.0($ LI60) } \\
\hline & & & \multicolumn{2}{|c|}{ ICU non COVID-19 } & 9 & $70.5 \pm 8.5$ & $63.7 \pm 34.7$ & $69.4 \pm 8.5$ & \multicolumn{2}{|c|}{$98.4 \pm 2.1(\mathrm{LI} 60)$} \\
\hline \multirow[t]{2}{*}{ Hoechter [96] } & \multirow{2}{*}{\multicolumn{2}{|c|}{ ROTEM delta }} & \multicolumn{2}{|c|}{ ICU COVID-19 } & 22 & $62(56-68)$ & $93(55-97)$ & $65(63-70)$ & \multicolumn{2}{|c|}{$6.5(4.5-9.0)$} \\
\hline & & & \multicolumn{2}{|c|}{ ICU non-COVID-19 } & 14 & $70(58-78)$ & $84(80-113)$ & $66(53-72)$ & \multicolumn{2}{|l|}{$5.0(2.3-7.0)$} \\
\hline \multirow[t]{2}{*}{ Spiezia [97] } & \multirow{2}{*}{\multicolumn{2}{|c|}{ ROTEM sigma }} & \multicolumn{2}{|c|}{ Ward COVID-19 } & 56 & $66 \pm 9$ & $48 \pm 15^{*}$ & $71 \pm 6^{\S}$ & \multicolumn{2}{|c|}{ 1-2 (Range) (ML) } \\
\hline & & & \multicolumn{2}{|c|}{ Ward non-COVID-19 } & $19 \quad 56$ & $70 \pm 11$ & $62 \pm 16$ & $69 \pm 6$ & \multicolumn{2}{|c|}{ 2-3 (Range) (ML) } \\
\hline \multirow[t]{2}{*}{ Roh [98] } & \multirow{2}{*}{\multicolumn{2}{|c|}{ ROTEM }} & \multirow{2}{*}{\multicolumn{2}{|c|}{$\begin{array}{l}\text { ICU COVID-19 } \\
\text { ICU surgical patients }\end{array}$}} & 30 & $108 \pm 54 *$ & N/A & $75 \pm 5^{\circ}$ & \multirow{2}{*}{\multicolumn{2}{|c|}{$\begin{array}{l}\text { N/A } \\
\text { N/A }\end{array}$}} \\
\hline & & & & & ts 30 & $57 \pm 31$ & N/A & $65 \pm 8$ & & \\
\hline \multicolumn{11}{|l|}{ B } \\
\hline Study & pe VET & Popula & & n. patients & $\mathrm{CT}$ & $\mathrm{CTH}$ & CTR & $\mathrm{CS}$ & PCS & FCS \\
\hline \multirow[t]{2}{*}{ Masi [99] C } & \multirow[t]{2}{*}{ Quantra } & $\begin{array}{l}\text { ICU CC } \\
19\end{array}$ & VID- & 17 & $152(30-171)$ & $\begin{array}{l}130(117- \\
152)\end{array}$ & $1.1(1.1-1.3)$ & $\begin{array}{l}49.9(38.5- \\
68)^{*}\end{array}$ & $\begin{array}{l}38.5(28.85- \\
51.2)^{\S}\end{array}$ & $\begin{array}{l}12.8(6.35- \\
20.85)^{*}\end{array}$ \\
\hline & & $\begin{array}{r}\text { ICU no } \\
\text { COV }\end{array}$ & $\begin{array}{l}\mathrm{n}- \\
\mathrm{D}-19\end{array}$ & 11 & $\begin{array}{l}127(137- \\
193)\end{array}$ & $\begin{array}{l}130(114- \\
150)\end{array}$ & $1.1(1.0-1.2)$ & $\begin{array}{l}24.9(20.2- \\
42.0)\end{array}$ & $\begin{array}{l}20.8(17.9- \\
33.6)\end{array}$ & $\begin{array}{l}6.1 \\
(4.0-8.2)\end{array}$ \\
\hline
\end{tabular}

$I C U$ intensive care unit, VET viscoelastic test, TEG thromboelastography, ROTEM rotational thromboelastometry, $C T$ clotting time, $R$ reaction time, $K$ time, $C F T$ clot formation time, $M A$ maximum amplitude, $M C F$ maximum clot formation, $L Y 30$ the decrease in clot firmness in percentage of maximum amplitude (MA) 30 min after MA, LI30-LI60 the residual clot firmness in percentage of maximum clot firmness 30 min (LI30) or $60 \mathrm{~min}$ (LI60) after CT, $M L$ maximum lysis, CTH clot time with heparinase, CTR clot time ratio, $C S$ clot stiffness, $P C S$ platelet clot stiffness, FCS fibrinogen clot stiffness, N/A not available

${ }^{*} \mathrm{p}<0.001,{ }^{\circ} \mathrm{p}<0.0001,{ }^{\S} \mathrm{p}<0.05$

(MCF) in COVID-19 patients than in surgical patients was reported. Probably, the slower coagulation kinetics in COVID-19 patients depended on the inability to match COVID-19 patients to analogous non-COVID-19 controls with similar critical illness severity.

In conclusion, from the literature data available, based on the use of VETs, it is possible to assume that CAC is characterized by a more severe state of hypercoagulability than coagulopathy correlated to bacterial infection.

The summary of reported studies is shown in Table 3.

\section{Care level in COVID-19 patients: what can we learn from the VETs?}

COVID-19 is a viral disease that involves multiple organ systems while usually presenting as an acute febrile illness [100, 101]. Acute COVID-19 has three distinct phases: early infection, pulmonary involvement and severe hyperinflammation with systemic involvement [102]. Conventional coagulation tests (PT and aPTT levels) did not significantly differ between mild and severe COVID-19 cases [103]. Keeping in mind that inflammation-induced coagulopathy is a very dynamic process, the detection of coagulation parameters with VETs could help identify atrisk patients in their course of illness. Recently, Mitrovic et al. [104], basing on ROTEM analysis of different severity of disease, observed that a hypercoagulable state characterized by clot formation acceleration, high clot strength and reduced fibrinolysis, was more frequent in advanced disease patients and patients with high interleukin-6. An Indian retrospective study, using TEG analysis, confirmed the presence of hypercoagulability that was more pronounced in severe forms of COVID-19 patients admitted to ICU [105].

Four studies [68, 106-108] have considered the difference in hypercoagulable profile and fibrinolysis between patients with COVID-19 admitted to ICU or specialized ward and general ward. Boscolo et al. [106] demonstrated, using ROTEM device, that COVID-19 patients with mild respiratory failure admitted to the internal medical ward had less severe hypercoagulability than critically ill patients. In particular, they presented lower FIBTEM MCF values related to fibrinogen levels than ICU patients. Tsantes et al. [68] confirmed that the degree of hypercoagulability in COVID19 infection might be associated with disease severity. In 
the same line Almskog et al. [107] found longer EXTEM CFT, lower EXTEM MCF and FIBTEM MCF in COVID19 patients with mild respiratory failure admitted to general ward compared with COVID-19 patients admitted to specialized ward with severe respiratory failure. However, they found in severe COVID-19 patients longer EXTEM CT than in others, even if the authors could not exclude that part of the prolonged EXTEM CT observed in severe COVID-19 patients could be driven by heparin effect.

Regarding fibrinolysis, Blasi et al. [108] compared ROTEM parameters of 12 patients admitted to the ICU with those of 11 patients admitted to a general ward; they found greater hypofibrinolysis (LI60) in ICU patients than in others [100 (100-99.3), vs. 96 (94.4-97.8), p <0.001].

In conclusion, hypercoagulable and hypofibrinolytic states are correlated with more severe COVID-19 infection and higher incidence of complications. This suggests the importance of need for different thromboprophylaxis approach for different severity of disease.

\section{Limitations of viscoelastic methods}

VETs are attractive because they address clot mechanical properties and fibrinolysis, but data on the use of VETs in COVID-19 patients has a number of limitations.

First, Kruse et al. [37] reported how the combination of EXTEM ML and maximum D-dimer can be used to stratify the risk of thrombotic events in critically ill COVID-19 patients. These results have to be confirmed in bigger observational trials and the effectiveness of a goal-directed anticoagulation management has to be assessed by interventional trials. Second, there is a lack of information to correlate VET data with the extent of thromboembolic damage due to the difficulty in performing instrumental examinations in COVID-19 patients with severe form of pneumonia. Third, most of published studies are single-center retrospective studies with a low sample size. Multicenter, observational trials with much bigger patient population are actually running (e.g. ROHOCO study in 10 countries and 14 hospital, recruiting more than 500 hospitalized COVID-19 patients (DRKS00023934) and TARGET study initiated by Kurizky et al. [109]).

In regard to methodology, VETs determination of fibrinogen contribution to clot firmness is based on the exclusion of platelets role to clot amplitude. The sensitivity of VETs to fibrinogen levels is quite variable depending on the test methodology [110]. Several studies demonstrated that the correlation between Clauss fibrinogen and ROTEM FIBTEM is superior to the correlation between Clauss fibrinogen and TEG FF assay since abciximab provides a less effective inhibition compared to cytochalasin D, and therefore TEG FF assay is associated with more "platelet noise" [111-113].

In regard to fibrinolysis, it is initiated by the formation of fibrin and it is tightly controlled by a series of cofactors, inhibitors, and receptors [114]. Plasmin is the central enzyme in fibrinolysis and is activated from plasminogen by either of two primary serine proteases, tPA and uPA. However, in VETs, plasminogen activators are most often so low that fibrinolysis is negligible [115]; VETs results can be influence by hyperfibrinogenemia that is common in COVID-19. To overcome these limitations, some authors added exogenous tPA to induce fibrinolysis and validated a novel whole blood ROTEM (tPATEM) [50, 59, 116]. Notably, tPATEM assesses fibrinolysis resistance and not fibrinolysis shutdown; they have two different pathomechanisms [117]. However, such modified commercial reagents require manual pipetting that increases inter-observed variability. Added to this is the fact that the new VET device could lack sensitivity to the effect on the transient increase of tPA that could be present during initial stages of the COVID-19 [49].

Another important issue is the contribution of platelets to thrombotic process. VETs results are dependent on platelet activation by thrombin generated in the sample, making them insensitive to platelet inhibition by aspirin, non-steroidal anti-inflammatory medications or P2Y12 antagonists. They are also insensitive to disorders of primary hemostasis such as von Willebrand disease or defects in platelets adhesion. Therefore, VETs should be complemented by platelet function testing such as whole blood impedance aggregometry as published by Correa et al. in COVID-19 patients [118]. However, the effect of COVID-19 on platelet function seems to be lower compared to bacterial sepsis [95].

Finally, the lack of standardization of the VET devices can limit data comparison across different laboratories. ROTEM sigma, a close, cartridge based, fully-automatized viscoelastic testing system, reduces intra and inter-assay variability and therefore could allow more standardized and comparable data.

\section{Conclusions}

VETs assess dynamic aspects of hemostasis, regarding both clot formation and dissolution so allowing to evaluate a "dynamic" modification of hemostasis over time. They could provide to clinicians more information about the CAC, identifying at the patient bedside the presence of a hypercoagulable state and hypofibrinolysis, that are more evident than in coagulopathy during the sepsis.

In regard to VTE prediction, the results of VETs analysis demonstrate a hypercoagulable state that is not predictive for thrombotic events in critically ill COVID-19 patients. 
The clinical application of VETs in patients with severe COVID-19 infection should be combined with biohumoral parameters (i.e. D-dimer) [37, 49].

Future studies on large patient populations should define the usefulness of VETs as prognostic markers of micro- and macrothrombosis in severe COVID-19 patients to improve morbidity and mortality. The dynamic coagulative approach based on the use of VETs, associated to laboratory tests, might help to guide a personalized anticoagulant strategy, well knowing that "one size does not fit all".

Author contributions VP, LG conceived and wrote the paper. MP contributed to the literature review. PD and DP edited drafts of the manuscript. All authors reviewed the final manuscript.

Funding None.

Data availability Not applicable.Consent to publication Not applicable.

\section{Declarations}

Conflicts of interest The authors declare that they have no conflicts of interest related to the present work.

Ethical approval Not applicable.

Informed consent Not applicable.

\section{References}

1. Klok FA, Kruip MJHA, van der Meer NJM, Arbous MS, Gommers DAMPJ, Kant KM, et al. Incidence of thrombotic complications in critically ill ICU patients with COVID-19. Thromb Res. 2020;191:145-7. https://doi.org/10.1016/j.thromres.2020.04.013.

2. Klok FA, Mjha K, van der Meer NJM, Arbous MS, Gommers D, Kant KM, et al. Confirmation of the high cumulative incidence of thrombotic complications in critically ill ICU patients with COVID-19: an updated analysis. Thromb Res. 2020;191:148-50. https://doi.org/10.1016/j.thromres.2020.04.041.

3. Middeldorp S, Coppens M, Haaps TF, Foppen M, Vlaar AP, Muller MCA, et al. Incidence of venous thromboembolism in hospitalized patients with COVID-19. J Thromb Haemost. 2020;18(8):1995-2002. https://doi.org/10.1111/jth.14888.

4. Varga Z, Flammer AJ, Steiger P, Haberecker M, Andermatt R, Zinkernagel AS, et al. Endothelial cell infection and endotheliitis in COVID-19. Lancet. 2020;395:1417-8. https://doi.org/10. 1016/S0140-6736(20)30937-5.

5. Xie Y, Wang X, Yang P, Zhang S. COVID-19 complicated by acute pulmonary embolism. Radiol Cardiothorac Imaging. 2020;2(2): e200067. https://doi.org/10.1148/ryct.2020200067.

6. do Espirito Santo DA, Lemos ACB, Miranda CH. In vivo demonstration of microvascular thrombosis in severe COVID-19 patients. J Thromb Thrombolysis. 2020;50(4):790-4. https:// doi.org/10.1183/13993003.02608-2020.
7. Tang N, Li D, Wang X, Sun Z. Abnormal coagulation parameters are associated with poor prognosis in patients with novel coronavirus pneumonia. J Thromb Haemost. 2020;18:844-7. https:// doi.org/10.1111/jth.14768.

8. Lippi G, Favaloro EJ. D-dimer is associated with severity of coronavirus disease 2019: a pooled analysis. Thromb Haemost. 2020;120(5):876-8. https://doi.org/10.1055/s-0040-1709650.

9. Fox SE, Akmatbekov A, Harbert JL, Li G, Brown JQ, Vander Heide RS. Pulmonary and cardiac pathology in African American patients with COVID-19: an autopsy series from New Orleans. Lancet Respir Med. 2020;8(7):681-6. https:// doi.org/10.1016/S2213-2600(20)30243-5.

10. Thachil J. All those D-dimers in COVID-19. J Thromb Haemost. 2020;18(8):2075-6. https://doi.org/10.1111/jth.14939.

11. Hunt BJ, Levi M. Re The source of elevated plasma D-dimer levels in COVID-19 infection. Br J Haematol. 2020;190(3):e133-4. https://doi.org/10.1111/bjh.16907.

12. Han H, Yang L, Liu R, Liu F, Wu KL, Li J, et al. Prominent changes in blood coagulation of patients with SARS-CoV-2 infection. Clin Chem Lab Med. 2020;58(7):1116-20. https:// doi.org/10.1515/cclm-2020-0188.

13. Terpos E, Ntanasis-Stathopoulos I, Elalamy I, Kastritis E, Sergentanis TN, Politou M, et al. Hematological findings and complications of COVID-19. Am J Hematol. 2020;7:834-47. https://doi.org/10.1002/ajh.25829.

14. Ganter MT, Hofer CK. Coagulation monitoring: current techniques and clinical use of viscoelastic point-of-care coagulation devices. Anesth Analg. 2008;106(5):1366-75. https://doi. org/10.1213/ane.0b013e318168b367.

15. Whiting D, DiNardo JA. TEG and ROTEM: technology and clinical applications. Am J Hematol. 2014;89(2):228-32. https://doi.org/10.1002/ajh.23599.

16. Schoechi N, Nienaber U, Hofer G, Voelckel W, Jambor C, Scharbert G, et al. Goal-directed coagulation management of major trauma patients using rotation thromboelastometry (ROTEM)-guided administration of fibrinogen and prothrombin complex concentrate. Crit Care. 2010;14:R55. https://doi. org/10.1186/cc8948.

17. Ferrante EA, Blasier KR, Givens TB, Lloyd CA, Fisher TJ, Viola F. A novel device for the evaluation of hemostatic function in critical care settings. Anesth Analg. 2016;123(6):13729. https://doi.org/10.1213/ANE.0000000000001413.

18. Kang Y. Thromboelastography in liver transplantation. Semin Thromb Hemost. 1995;21(Suppl 4):34-44.

19. Shore-Lesserson L, Manspeizer HE, DePerio M, Francis S, Vela-Cantos F, Ergin MA. Thromboelastography-guided transfusion algorithm reduces transfusions in complex cardiac surgery. Anesth Analg. 1999;88(2):312-9. https://doi.org/10. 1097/00000539-199902000-00016.

20. Toukh M, Siemens DR, Black A, Robb S, Leveridge M, Graham $\mathrm{CH}$, et al. Thromboelastography identifies hypercoagulability and predicts thromboembolic complications in patients with prostate cancer. Thromb Res. 2014;133(1):88-95. https:// doi.org/10.1016/j.thromres.2013.10.007.

21. Brill JB, Badiee J, Zander AL, Wallance JD, Lewis PR, Sise $\mathrm{MJ}$, et al. The rate of deep vein thrombosis doubles in trauma patients with hypercoagulable thromboelastography. J Trauma Acute Care Surg. 2017;83(3):413-9. https://doi.org/10.1097/ TA.0000000000001618.

22. McCully BH, Connelly CR, Fair KA, Holcomb JB, Fox EE, Wade CE, et al. Onset of coagulation function recovery is delayed in severely injured trauma patients with venous thromboembolism. J Am Coll Surg. 2017;225(1):42-51. https://doi. org/10.1016/j.jamcollsurg.2017.03.001.

23. Branco BC, Inaba K, Ives C, Okoye O, Shulman I, David JS, et al. Thromboelastogram evaluation of the impact of 
hypercoagulability in trauma patients. Shock. 2014;41(3):2007. https://doi.org/10.1097/SHK.0000000000000109.

24. Johansson PI, Stensballe J, Vindeløv N, Perner A, Espersen K. Hypocoagulability, as evaluated by thrombelastography, at admission to the ICU is associated with increased 30-day mortality. Blood Coagul Fibrinolysis. 2010;21(2):168-74. https:// doi.org/10.1097/MBC.0b013e3283367882.

25. Arcelus JI, Traverso CI, Caprini JA. Thromboelastography for the assessment of hypercoagulability during general surgery. Semin Thromb Hemost. 1995;21(Suppl 4):21-6. https://doi. org/10.1055/s-0032-1313617.

26. Prisco D, Paniccia R. Point-of care testing of hemostasis in cardiac surgery. Thromb J. 2003;1(1):1. https://doi.org/10.1186/ 1477-9560-1-1.

27. Hartert H. Coagulation analysis with thromboelastography, a new method. Klin Wochenschr. 1948;26:577-658.

28. Muller MC, Meijers JC, Vroom MB, Juffermans NP. Utility of thromboelastography and/or thromboelastometry in adults with sepsis: a systematic review. Crit Care. 2014;18(1):R30. https:// doi.org/10.1186/cc13721.

29. Kim SJ, Wang IJ, Yeom SR, Cho SJ, Kim JH, Seok JP, et al. Usefulness of rotational thromboelastometry as a mortality predictor of hyperfibrinolysis in patients with severe trauma. Acute Crit Care. 2018;33(3):162-9. https://doi.org/10.4266/acc.2018. 00199.

30. Stettler GR, Moore EE, Moore HB, Nunns GR, Silliman CC, Banerjee A, et al. Redefining postinjury fibrinolysis phenotypes using two viscoelastic assays. J Trauma Acute Care Surg. 2019;86(4):679-85. https://doi.org/10.1097/TA.0000000000 002165.

31. Corey FS, Walker WF. Sonic estimation of elasticity via resonance: a new method of assessing hemostasis. Ann Biomed Eng. 2016;44:1405-24. https://doi.org/10.1007/s10439-015-1460-y.

32. Ferrante EA, Blasier KR, Givens TB, Lloyd CA, Fischer TJ, Viola F. A novel device for the evaluation of hemostatic function in critical care settings. Anesth Analg. 2016;123:1372-9. https:// doi.org/10.1213/ANE.0000000000001413.

33. Michelson EA, Cripps MW, Ray B, Winegar DA, Viola F. Initial clinical experience with the Quantra QStat System in adult trauma patients. Trauma Surg Acute Care Open. 2020;5(1): e000581. https://doi.org/10.1136/tsaco-2020-000581.

34. Adamzik M, Eggmann M, Frey UH, Görlinger K, BröckerPreuss M, Marggraf G, et al. Comparison of thromboelastometry with procalcitonin, interleukin $6, \mathrm{C}$-reactive protein as diagnostic tests for severe sepsis in critically ill adults. Crit Care. 2010;14(5):R178. https://doi.org/10.1186/cc9284.

35. Schmitt FCF, Manolov V, Morgenstern J, Fleming T, Heitmeier $\mathrm{S}$, Uhle F, et al. Acute fibrinolysis shutdown occurs early in septic shock and is associated with increased morbidity and mortality: results of an observational pilot study. Ann Intensive Care. 2019;9(1):19. https://doi.org/10.1186/s13613-019-0499-6.

36. Creel-Bulos C, Auld SC, Caridi-Scheible M, Barker NA, Friend $\mathrm{S}$, Gaddh M, et al. Fibrinolysis shutdown and thrombosis in a COVID-19 ICU. Shock. 2021;55(3):316-20. https://doi.org/10. 1097/SHK.0000000000001635.

37. Kruse JM, Magomedov A, Kurreck A, Münch FH, Koerner R, Kamhieh-Milz J, et al. Thromboembolic complications in critically ill COVID-19 patients are associated with impaired fibrinolysis. Crit Care. 2020;24(1):676. https://doi.org/10.1186/ s13054-020-03401-8.

38. Antoniak S, Mackman N. Multiple roles of the coagulation protease cascade during virus infection. Blood. 2014;123:2605-13. https://doi.org/10.1182/blood-2013-09-526277.

39. Chauhan AJ, Wiffen LJ, Brown TP. COVID-19: a collision of complement, coagulation and inflammatory pathways. J Thromb Haemost. 2020;18:2110-7. https://doi.org/10.1111/jth.14981.
40. Escher R, Breakey N, Lammle B. Severe COVID-19 infection associated with endothelial activation. Thromb Res. 2020;190:62. https://doi.org/10.1016/j.thromres.2020.04.014.

41. Ackermann M, Verleden SE, Kuehnel M, Haverich A, Welte T, Laenger F, et al. Pulmonary vascular endotheliitis, thrombosis and angiogenesis in COVID-19. N Engl J Med. 2020;383(2):120 8. https://doi.org/10.1056/NEJMoa2015432.

42. Menter T, Haslbauer JD, Nienhold R, Savic S, Hopfer H, Deigenedesh N, et al. Postmortem examination of COVID19 patients reveals diffuse alveolar damage with severe capillary congestion and variegated findings of lungs and other organs suggesting vascular dysfunction. Histopathology. 2020;77(2):198-209. https://doi.org/10.1111/his.14134.

43. Hartmann M, Ozlügedik S, Peters J. Thiopental inhibits lipopolysaccharide-induced tissue factor expression. Anesth Analg. 2009;109(1):109-13. https://doi.org/10.1213/ane.0b013 e3181a27cfb.

44. Adamzik M, Schäfer S, Frey UH, Becker A, Kreuzer M, Winning S, et al. The NFKB1 promoter polymorphism (-94ins/ delATTG) alters nuclear translocation of NF-kappaB1 in monocytes after lipopolysaccharide stimulation and is associated with increased mortality in sepsis. Anesthesiology. 2013;118(1):123-33. https://doi.org/10.1097/ALN.0b013 e318277a652.

45. Meltzer ME, Lisman T, de Groot PG, Meijers JC, le Cessie S, Doggen CJ, et al. Venous thrombosis risk associated with plasma hypofibrinolysis is explained by elevated plasma levels of TAFI and PAI-1. Blood. 2010;116(1):113-21. https://doi.org/10.1182/ blood-2010-02-267740.

46. Gralinski LE, Bankhead A, Jeng S, Manachery VD, Proll $\mathrm{S}$, Belisle SE, et al. Mechanisms of severe acute respiratory syndrome coronavirus-induced acute lung injury. MBio. 2013;4(4):e00271-13. https://doi.org/10.1128/mBio.00271-13.

47. Boss K, Kribben A, Tyczynski B. Pathological findings in rotation thromboelastometry associated with thromboembolic events in COVID-19 patients. Thromb J. 2021;19(1):10. https://doi.org/ 10.1186/s12959-021-00263-0.

48. Görlinger K, Levy JH. COVID-19-associated coagulopathy. Less fibrinolysis can be more harmful! Anesthesiology. 2021;134(3):366-9. https://doi.org/10.1097/ALN.0000000000 003688 .

49. Wright FL, Vogler TO, Moore EE, Moore HB, Wohlauer MV, Urban S, et al. Fibrinolysis shutdown correlation with thromboembolic events in severe COVID-19 infection. J Am Coll Surg. 2020;231:193-203. https://doi.org/10.1016/j.jamcollsurg.2020. 05.007 .

50. Nougier C, Benoit R, Simon M, Desmurs-Clavel H, Marcotte $\mathrm{G}$, Argaud L, et al. Hypofibrinolytic state and high thrombin generation may play a major role in SARS-CoV-2 associated thrombosis. J Thromb Haemost. 2020;18:2215-9. https://doi.org/ 10.1111/jth.15016.

51. Ciceri F, Berretta L, Scandroglio AM, Colombo S, Landoni G, Ruggeri A, et al. Microvascular COVID-19 lung vessels obstructive thromboinflammatory syndrome (MicroCLOTS): an atypical acute respiratory distress syndrome working hypothesis. Crit Care Resusc. 2020;15(22):95-7.

52. Thachil J, Tang N, Gando S, Falanga A, Cattaneo M, Levi $\mathrm{M}$, et al. ISTH interim guidance on recognition and management of coagulopathy in COVID-19. J Thromb Heamost. 2020;18(5):1023-6. https://doi.org/10.1111/jth.14810.

53. Danzi GB, Loffi M, Galeazzi G, Gherbesi E. Acute pulmonary embolism and COVID-19 pneumonia: a random association? Eur Heart J. 2020;41:1858. https://doi.org/10.1093/eurheartj/ehaa2 54. 
54. Xie Y, Wang X, Yang P. COVID-19 complicated by acute pulmonary embolism. Radiol Cardiothorac Imaging. 2020;2: e200067. https://doi.org/10.1148/ryct.2020200067.

55. Panigada M, Bottino N, Tagliabue P, Grasselli G, Novembrino C, Chantarangkul V, et al. Hypercoagulability of COVID-19 patients in intensive care unit: a report of thromboelastography findings and other parameters of hemostasis. J Thromb Haemost. 2020;18(7):1738-42. https://doi.org/10.1111/jth.14850.

56. Maatman TK, Jalali F, Feizpour C, Douglas A II, McGuire SP, Kinnaman G, et al. Routine venous thromboembolism prophylaxis may be inadequate in the hypercoagulable state of severe coronavirus disease 2019. Crit Care Med. 2020;48(9):783-90. https://doi.org/10.1097/CCM.0000000000004466.

57. Spiezia L, Boscolo A, Poletto F, Cerruti L, Tiberio I, Campello $\mathrm{E}$, et al. COVID-19-related severe hypercoagulability in patients admitted to intensive care unit for acute respiratory failure. Thromb Haemost. 2020;120(6):998-1000. https://doi.org/10. 1055/s-0040-1710018.

58. Pavoni V, Gianesello L, Pazzi M, Stera C, Meconi T, Frigeri FC. Evaluation of coagulation function by rotational thromboelastometry in critically ill patients with severe COVID-19 pneumonia. J Thromb Thrombolysis. 2020;50(2):281-6. https://doi.org/10. 1007/s11239-020-02130-7.

59. Hulshof AM, Bruggemann RAG, Mulder MMG, van de Berg TW, Sels JWEM, Olie RH, et al. Serial EXTEM, FIBTEM, and tPA rotational thromboelastometry observations in the Maastricht Intensive Care COVID Cohort-Persistence of hypercoagulability and hypofibrinolysis despite anticoagulation. Front Cardiovasc Med. 2021;8: 654174. https://doi.org/10.3389/fcvm. 2021.654174

60. Ranucci M, Ballotta A, Di Dedda U, Bayshnikova E, Dei Poli M, Resta M, et al. The procoagulant pattern of patients with COVID-19 acute respiratory distress syndrome. J Thromb Haemost. 2020;18(7):1747-51. https://doi.org/10.1111/jth.14854.

61. Van der Linden J, Almskog L, Liliequist A, Grip J, Fux T, Rysz $\mathrm{S}$, et al. Thromboembolism, hypercoagulopathy, and antiphospholipid antibodies in critically ill coronavirus disease 2019 patients: a before and after study enhanced anticoagulation. Crit Care Explor. 2020;2: e0308. https://doi.org/10.1097/CCE.00000 00000000308.

62. Yuriditsky E, Horowitz JM, Merchan C, Ahuja T, Brosnahan SB, McVoy L, et al. Thromboelastography profiles of critically ill patients with coronavirus disease 2019. Crit Care Med. 2020;48:1319-26. https://doi.org/10.1097/CCM.0000000000 004471 .

63. Ibanez L, Gluck S, Strickland RM, Reddi BJ. Evaluation of coagulation status using viscoelastic testing in intensive care patients with coronavirus disease 2019 (COVID-19): an observational point prevalence cohort study. Aust Crit Care. 2021;34:155-9. https://doi.org/10.1016/j.aucc.2020.07.003.

64. Ibanez C, Perdomo J, Calvo A, Ferrado C, Reverter JC, Tassies D, et al. High D dimers and low global fibrinolysis coexist in COVID-19 patients: what is going on in there? J Thromb Thrombolysis. 2020;15:1-5. https://doi.org/10.1007/ s11239-020-02226-0.

65. Pavoni V, Gianesello L, Pazzi M, Horton A, Suardi LR. Derangement of the coagulation process using subclinical markers and viscoelastic measurements in critically ill patients with coronavirus disease 2019 pneumonia and non-coronavirus disease 2019 pneumonia. Blood Coagul Fibrinolysis. 2021;32(2):80-6. https:// doi.org/10.1097/MBC0000000000000971.

66. Sadd C, Rowe T, Nazeef M, Kory P, Sultan S, Faust H. Thromboelastography to detect hypercoagulability and reduced fibrinolysis in coronavirus disease 2019 acute distress respiratory syndrome patients. Crit Care Explor. 2020;2(9): e0192. https://doi. org/10.1097/CCE.0000000000000192.
67. Bocci MG, Maviglia R, Consalvo LM, Grieco DL, Montini L, Mercurio G, et al. Thromboelastography clot strength profiles and effect of systemic anticoagulation in COVID-19 acute respiratory distress syndrome; a prospective, observational study. Eur Rev Med Pharmacol Sci. 2020;24(23):12466-9. https://doi. org/10.26355/eurrev_202012_24043.

68. Tsantes AE, Frantzeskaki F, Tsantes AG, Rapti E, Rizos M, Kokoris SI, et al. The haemostatic profile in critically ill COVID19 patients receiving therapeutic anticoagulant therapy. Medicine (Baltim). 2020;99(47):e23365. https://doi.org/10.1097/MD. 0000000000023365.

69. Brown W, Lunati M, Maceroli M, Ernst A, Staley C, Johnson $\mathrm{R}$, et al. Ability of thromboelastography to detect hypercoagulability: a systematic review and meta-analysis. J Orthop Trauma. 2019;34(6):278-86. https://doi.org/10.1097/BOT. 0000000000001714.

70. Gary J, Schneider P, Galpin M, Radwan Z, Munz J, Achor $\mathrm{T}$, et al. Can thromboelastography predict venous thromboembolic events in patients with extremity trauma? J Orthop Trauma. 2016;30:294-8. https://doi.org/10.1097/BOT.00000 00000000523.

71. Brill JB, Badiee J, Zander AL, Wallace JD, Lewis PR, Sise MJ, et al. The rate of deep vein thrombosis doubles in trauma patients with hypercoagulable thromboelastography. J Trauma Acute Care Surg. 2017;83:413-9. https://doi.org/10.1097/TA. 0000000000001618.

72. Cotton BA, Minei KM, Radwan ZA, Matijevic N, Pivalizza E, Podbielski J, et al. Admission rapid thromboelastography predicts development of pulmonary embolism in trauma patients. J Trauma Acute Care Surg. 2012;72:1470-5. https://doi.org/ 10.1097/TA.0b013e31824d56ad.

73. Dimitrova-Karamfilova A, Patokova Y, Solarova T, Petrova I, Natchev G. Rotation thromboelastography for assessment of hypercoagulation and thrombosis in patients with cardiovascular diseases. J Life Sci. 2012;6:28-35.

74. Faraoni D, Emani S, Halpin E, Bernier R, Emani SM, DiNardo JA, et al. Relationship between transfusion of blood products and the incidence of thrombotic complications in neonates and infants undergoing cardiac surgery. J Cardiothorac Vasc Anesth. 2017;31(6):1943-8. https://doi.org/10.1053/j.jvca. 2017.04.039.

75. Hincker A, Feit J, Sladen RN, Wagener G. Rotational thromboelastometry predicts thromboembolic complications after major non-cardiac surgery. Crit Care. 2014;18(5):549.

76. Zanetto A, Senzolo M, Vitale A, Cillo U, Radu C, Sartorello F, et al. Thromboelastometry hypercoagulable profiles and portal vein thrombosis in cirrhotic patients with hepatocellular carcinoma. Dig Liver Dis. 2017;49(4):440-5. https://doi.org/10.1186/ s13054-014-0549-2.

77. Kamel Y, Hassanin A, Ahmed AR, Gad E, Afifi M, Khalil M, Görlinger K, Yassen K. Perioperative thromboelastometry for adult living donor liver transplant recipients with a tendency to hypercoagulability: a prospective observational cohort study. Transfus Med Hemother. 2018;45(6):404-12. https://doi.org/ $10.1159 / 000489605$.

78. Mortus JR, Manek SE, Nrubaker LS, Loor M, Cruz MA, Trautner BW, et al. Thromboelastographic results and hypercoagulability syndrome in patients with coronavirus disease 2019 who are critically ill. JAMA Netw Open. 2020;3: e2011192. https:// doi.org/10.1001/jamanetworkopen.2020.11192.

79. Shah A, Donovan K, McHugh A, Pandey M, Aaron L, Bradbury CA, et al. Thrombotic and haemorrhagic complications in critically ill patients with COVID-19: a multicentre observational study. Crit Care. 2020;24(1):561. https://doi.org/10.1186/ s13054-020-03260-3. 
80. Stattin K, Lipvsey M, Andersson H, Ponten E, Anderberg SB, Gradin A, et al. Inadequate prophylactic effect of low-molecular weight heparin in critically ill COVID-19 patients. J Crit Care. 2020;60:249-52. https://doi.org/10.1016/j.jcrc.2020.08.026.

81. van Veenendaal N, Scheeren TWL, Meijer K, van der Voort PHJ. Rotational thromboelastometry to assess hypercoagulability in COVID-19 patients. Thromb Res. 2020;196:379-81. https://doi. org/10.1016/j.thromres.2020.08.046.

82. Wuillemin WA, Korte W, Waser G, Lämmle B. Usefulness of the D-dimer/fibrinogen ratio to predict deep venous thrombosis. J Thromb Haemost. 2005;3(2):385-7. https://doi.org/10.1111/j. 1538-7836.2004.01121.x.

83. Alvarez-Perez FJ, Castelo-Branco M, Alvarez-Sabin J. Usefulness of measurement of fibrinogen, D-dimer, D-dimer/fibrinogen ratio, $\mathrm{C}$ reactive protein and erythrocyte sedimentation rate to assess the pathophysiology and mechanism of ischaemic stroke. J Neurol Neurosurg Psychiatry. 2011;82(9):986-92. https://doi. org/10.1136/jnnp.2010.230870.

84. Salem N, Atallah B, El Nekidy WS, Sadik ZG, Park MW, Mallat J. Thromboelastography findings in critically ill COVID-19 patients. J Thromb Thrombolysis. 2020;4:1-5. https://doi.org/10. 1007/s11239-020-02300-7.

85. Talasaz AH, Sadeghipour P, Kakavand H, Aghakouchakzadeh M, Kordzadem-Irermani E, van Tassell BW, et al. Recent randomized trials of antithrombotic therapy of patients with COVID19: JACC state of art review. J Am Coll Cardiol. 2021;77:190321. https://doi.org/10.1016/j.jacc.2021.02.035.

86. Hunt BJ, De Paula EV, McLintock C, Dumantepe M. Prophylactic anticoagulation for patients in hospital with COVID-19: riskbenefit balance may depend on illness severity. BMJ. 2021;372: n487. https://doi.org/10.1136/bmj.n487.

87. Görlinger K, Almutawah H, Almutawaa F, Alwabari M, Alsultan $\mathrm{Z}$, Almajed J, et al. The role of rotational thromboelastometry during the COVID-19 pandemic: a narrative review. Korean J Anesthesiol. 2021;74(2):91-102. https://doi.org/10.4097/kja. 21006.

88. Kong R, Hutchinson N, Görlinger K. Hyper- and hypocoagulability in COVID-19 as assessed by thromboelastometry. Two case reports. Korean J Anesthesiol. 2020. https://doi.org/10.4097/kja. 20327.

89. Görlinger K, Pérez-Ferrer A, Dirkmann D, Saner F, Maegele M, Calatayud ÁAP, et al. The role of evidence-based algorithms for rotational thromboelastometry-guided bleeding management. Korean J Anesthesiol. 2019;72(4):297-322. https://doi.org/10. 4097/kja.19169.

90. Campello E, Farina F, Spiezia L, Maggiolo S, Palmieri A, Sartorello F, et al. Thromboelastometry profiles in patients undergoing thrombolytic therapy for acute ischaemic stroke. Thromb Haemost. 2016;115(6):1231-4. https://doi.org/10.1160/ TH15-10-0798.

91. Violi F, Cangemi R, Calvieri C. Pneumonia, thrombosis and vascular disease. J Thromb Haemost. 2014;12:1391-400. https://doi. org/10.1111/jth.12646.

92. Vail GM, Xie YI, Haney DJ, Barnes CJ. Biomarkers of thrombosis, fibrinolysis, and inflammation in patients with severe sepsis due to community-acquired pneumonia with and without Streptococcus pneumoniae. Infection. 2009;37:358-64. https://doi.org/ 10.1007/s15010-008-8128-6.

93. Iba T, Levy JH. Sepsis-induced coagulopathy and disseminated intravascular coagulation. Anesthesiology. 2020;132(5):123845. https://doi.org/10.1097/ALN.0000000000002122.

94. Adamzik M, Langemeier T, Frey UH, Görlinger K, Saner F, Eggebrecht H, et al. Comparison of thromboelastometry with simplified acute physiology score II and sequential organ failure assessment scores for the prediction of 30-day survival: a cohort study. Shock. 2011;35(4):339-42. https://doi.org/10.1097/SHK. 0b013e318204bff6.

95. Adamzik M, Görlinger K, Peters J, Hartmann M. Whole blood impedance aggregometry as a biomarker for the diagnosis and prognosis of severe sepsis. Crit Care. 2012;16(5):R204. https:// doi.org/10.1186/cc11816.

96. Hoechter DJ, Becker-Pennrich A, Langrehr J, Bruegel M, Zwissler B, Schafer S, et al. Higher procoagulatory potential but lower DIC score in COVID-19 ARDS patients compared to non-COVID-19 ARDS patients. Thromb Res. 2020;196:186-92. https://doi.org/10.1016/j.thromres.2020.08.030.

97. Spiezia L, Campello E, Cola M, Poletto F, Cerruti L, Poretto A, et al. More severe hypercoagulable state in acute COVID-19 pneumonia as compared to other pneumonia. Mayo Clin Proc Innov Qual Outcomes. 2020;4(6):696-702. https://doi.org/10. 1016/j.mayocpiqo.2020.09.002.

98. Roh DJ, Eiseman K, Kirsch H, Yoh N, Boehme A, Agarwal $\mathrm{S}$, et al. Brief report: hypercoagulable viscoelastic blood clot characteristics in critically-ill COVID-19 patients and associations with thrombotic complication. J Trauma Acute Care Surg. 2021;90(1):e7-12. https://doi.org/10.1097/TA.0000000000 002963.

99. Masi P, Hekimian G, Lejeune M, Chommeloux J, Desnos C, Pineton De Chambrun M, et al. Systemic inflammatory response syndrome is a major contributor to COVID-19 associated coagulopathy. Circulation. 2020;142:611-4. https://doi.org/10.1161/ CIRCULATIONAHA.120.048925.

100. Guan WJ, Ni ZY, Hu Y, Liang WH, Ou CQ, He JX, et al. Clinical characteristics of coronavirus disease 2019 in China. N Engl J Med. 2020;382(18):1708-20. https://doi.org/10.1056/NEJMo a2002032.

101. Chen N, Zhou M, Dong X, Qu J, Gong F, Han Y, et al. Epidemiological and clinical characteristics of 99 cases of 2019 novel corona virus pneumonia in Wuhan, China: a descriptive study. Lancet. 2020;395(10223):507-13. https://doi.org/10.1016/ S0140-6736(20)30211-7.

102. Buja LM, Wolf DA, Zhao B, Akkanti B, McDonald M, Lelenwa $\mathrm{L}$, et al. The emerging spectrum of cardiopulmonary pathology of the coronavirus disease 2019 (COVID-19): report of 3 autopsies from Huston, Texas, and review of autopsy findings from other United States cities. Cardiovasc Pathol. 2020;48: 107233. https://doi.org/10.1016/j.carpath.2020.107233.

103. Gao Y, Li T, Han M, Li X, Wu D, Xu Y, et al. Diagnostic utility of clinical laboratory data determinations for patients with the severe COVID-19. J Med Virol. 2020;92:791-6. https://doi.org/ 10.1002/jmv.25770.

104. Mitrovic M, Sabljic N, Cvetkovic Z, Pantic N, Dakic AZ, Bukumiric Z, et al. Rotational thromboelastometry (ROTEM) profiling of COVID-19 patients. Platelets. 2021;9:1-7. https://doi.org/10. 1080/09537104.2021.1881949.

105. Saseedharan S, Talla VB, Chiluka A. Thromboelastography profile of patients with COVID-19 admitted to Intensive Care Unit: a single-center retrospective study from India. Indian J Crit Care Med. 2020;24(12):1218-22. https://doi.org/10.5005/jp-journ als-10071-23675.

106. Boscolo A, Spiezia L, Correale C, Sella N, Pesenti E, Beghetto L, et al. Different hypercoagulable profiles in patients with COVID19 admitted to the internal medicine ward and the intensive care unit. Thromb Haemost. 2020;120(10):1474-7. https://doi.org/10. 1055/s-0040-1714350.

107. Almskog LM, Wikman A, Svensson J, Wanecek M, Bottai M, van der Linden J, et al. Rotational thromboelastometry results are associated with care level in COVID-19. J Thromb Thrombolysis. 2020;17:1-9. https://doi.org/10.1007/s11239-020-02312-3.

108. Blasi A, von Meijenfeldt FA, Adelmijer J, Calvo A, Ibanez C, Perdomo J, et al. In vitro hypercoagulability and ongoing in vivo 
activation of coagulation and fibrinolysis in COVID-19 patients on anticoagulation. J Thromb Thrombolysis. 2020;18(10):264653. https://doi.org/10.1111/jth.15043.

109. Kurizky P, Nóbrega OT, Soares AASM, Aires RB, Albuquerque CP, Nicola AM, et al. Molecular and cellular biomarkers of COVID-19 prognosis: protocol for the prospective cohort TARGET Study. JMIR Res Protoc. 2021;10(3):e24211.

110. Ranucci M, Di Dedda U, Baryshnikova E. Trials and tribulation of viscoelastic-based determination of fibrinogen concentration. Anesth Analg. 2020;130(3):644-53. https://doi.org/10.1213/ ANE.0000000000004522.

111. Schlimp CJ, Solomon C, Ranucci M, Hochleitner G, Redl H, Schöchl H. The effectiveness of different functional fibrinogen polymerization assays in eliminating platelet contribution to clot strength in thromboelastometry. Anesth Analg. 2014;118(2):26976. https://doi.org/10.1213/ANE.0000000000000058.

112. Baksaas-Aasen K, Van Dieren S, Balvers K, Juffermans NP, Næss PA, Rourke C, et al. Data-driven development of ROTEM and TEG algorithms for the management of trauma hemorrhage: a prospective observational multicenter study. Ann Surg. 2019;270(6):1178-85. https://doi.org/10.1097/SLA.0000000000 002825 .

113. Ranucci M, Di Dedda U, Baryshnikova E. Trials and tribulations of viscoelastic-based determination of fibrinogen concentration.
Anesth Analg. 2020;130(3):644-53. https://doi.org/10.1213/ ANE.0000000000004522.

114. Chapin JC, Hajjar KA. Fibrinolysis and the control blood coagulation. Blood Rev. 2015;29(1):17-25. https://doi.org/10.1016/j. blre.2014.09.003.

115. Rijken DC, Hoegee-de Nobel E, Jie AF, Atsma DE, Schalij MJ, Nieuwenhuizen W. Development of a new test for the global fibrinolytic capacity in whole blood. J Thromb Haemost. 2008;6:151-7. https://doi.org/10.1111/j.1538-7836.2007. 02816.x.

116. Kuiper GJ, Kleinegris MC, van Oerle R, Spronk HMH, Lancé $\mathrm{MD}$, ten Cate $\mathrm{H}$, et al. Validation of a modified thromboelastometry approach to detect changes in fibrinolytic activity. Thromb J. 2016;14:1. https://doi.org/10.1186/s12959-016-0076-2.

117. Keragala CB, Medcalf RL, Myles PS. Fibrinolysis and COVID19: a tale of two sites? J Thromb Haemost. 2020;18(9):2430-2. https://doi.org/10.1111/jth.15017.

118. Corrêa TD, Cordioli RL, Campos Guerra JC, Caldin da Silva B, Dos Reis Rodrigues R, de Souza GM, et al. Coagulation profile of COVID-19 patients admitted to the ICU: an exploratory study. PLoS ONE. 2020;15(12):e0243604. https://doi.org/10. 1371/journal.pone.0243604.

Publisher's Note Springer Nature remains neutral with regard to jurisdictional claims in published maps and institutional affiliations. 